\title{
Flora das cangas da Serra dos Carajás, Pará, Brasil: Ochnaceae
}

\author{
Flora of the canga of the Serra dos Carajás, Pará, Brazil: Ochnaceae
}

Daniela Cristina Zappi ${ }^{1,2,3}$

\begin{abstract}
Resumo
Este estudo compreende as espécies de Ochnaceae que foram registradas sobre canga na Serra dos Carajás, estado do Pará, Brasil, incluindo chaves de identificação, descrições, ilustrações e comentários morfológicos das espécies. Foram registradas três espécies distribuídas em dois gêneros, Ouratea (O. castaneifolia e Ouratea racemiformis) e Sauvagesia tenella.
\end{abstract}

Palavras-chave: Amazônia, FLONA de Carajás, florística, Malpighiales.

\begin{abstract}
The present study comprises the Ochnaceae that were recorded on iron-stone (canga) at the Serra dos Carajás, Pará, Brazil. It includes identification keys, descriptions, illustrations and comments regarding the three species recorded in two genera, Ouratea (O. castaneifolia and Ouratea racemiformis), and Sauvagesia tenella. Key words: Amazon Rainforest, FLONA de Carajás, floristics, Malpighiales.
\end{abstract}

\section{Ochnaceae}

Composta por ervas, subarbustos, arbustos ou árvores, com estípulas pareadas perenes ou decíduas (deixando cicatrizes óbvias), folhas alternas com margens geralmente denteadas, serreadas ou ciliadas, flores geralmente actinomorfas, pentâmeras, dialipétalas, estames $5-10(-25)$, corona presente ou ausente, anteras poricidas ou rimosas, ovário súpero, 2-10-carpelar, sincárpico, óvulos 1-muitos por lóculo, placentação parietal, basal ou axilar, apenas um estilete, estigma punctado. Os frutos são capsulares ou esquizocarpos com 1-10 mericarpos suculentos sobre um receptáculo expandido (Sastre 2003; Yamamoto \& Sastre 2003).

Estudos recentes de filogenia molecular (Schneider et al. 2014)Ochnaceae s.str., Quiinaceae incluem tanto as Quiinaceae como as Medusagynaceae a nível de subfamília de
Ochnaceae, como Medusagynoideae e Quiinoideae, tratando também as Ochnoideae e Sauvagesioideae a nível de tribo. Apesar disso, foram aqui tratadas as Ochnaceae sensu stricto, excluindo as Quiinaceae que são monografadas neste mesmo volume (Botelho \& Rocha 2018). As Ochnaceae sensu stricto são uma família de distribuição tropical, com 14 gêneros no neotrópico, alguns deles, como Sauvagesia, Luxemburgia, Blastemanthus, Tyleria, Adenarake e Philacra associados a regiões de altitude (Sastre 2003; Yamamoto \& Sastre 2003). No Brasil ocorrem 13 gêneros e quase 200 espécies, das quais 117 são endêmicas (BFG 2015). No Brasil é cultivada Ochna serrulata Walp., proveniente da África do Sul, conhecida como planta-do-Mickey por causa da forma de seus frutos semelhantes aos de Ouratea. Esse tipo de fruto apresenta receptáculo expandido e duas (ou mais) drupas apocárpicas negras, assemelhando-se a orelhas.

\section{Chave de identificação dos gêneros de Ochnaceae das cangas da Serra dos Carajás}

1. Arbustos a arvoretas com ramos lenhosos, estípulas fimbriadas ausentes; flores amarelas; frutos drupáceos 1. Ouratea

1. Ervas a subarbustos delicados, estípulas fimbriadas presentes; flores rosadas; frutos capsulares

\footnotetext{
${ }^{1}$ Instituto Tecnológico Vale de Desenvolvimento Sustentável, R. Boaventura da Silva 955, 66055-090, Belém, PA, Brasil.

${ }^{2}$ Museu Paraense Emílio Goeldi, Coord. Botânica. Av. Perimetral, Terra Firme, 66077-830, Belém, PA, Brasil.

${ }^{3}$ Autor para correspondência: danielazappi14@gmail.com
} 


\section{Ouratea Aubl}

Arbustos a arvoretas, com estípulas escariosas pareadas, cedo decíduas, deixando cicatriz visível na base das folhas. Folhas simples, com margem levemente a fortemente denteada, nervuras caracteristicamente paralelas e eucamptódromas, atingindo quase a margem da folha e voltando-se para o ápice, e nervuras terciárias minutamente paralelas. Flores com pétalas vistosas, amarelas, sem corona ou estaminódios, estames com filamentos curtos, deiscência das anteras poricida, gineceu multicarpelar com estilete ginobásico. Frutos esquizocárpicos com receptáculo expandido e suculento portando 1 a 10 núculas separadas. Gênero com cerca de 300 espécies neotropicais (Fiaschi et al. 2010), conta com 119 espécies no Brasil das quais 22 ocorrem no Pará (BFG 2015).

\section{Chave de identificação das espécies de Ouratea ocorrentes nas cangas da Serra dos Carajás}

1. Folhas com margem espinescente; inflorescências eretas 1.1. Ouratea castaneifolia

1. Folhas com margem levemente serreada, não espinescente; inflorescências pêndulas

1.1. Ouratea castaneifolia (DC.) Engl., Fl. bras. 12(2): 309. 1876.

Fig. 1a-b; 2a-b

Arbusto a arvoreta 1,5-2 $\mathrm{m}$ alt., totalmente glabro. Estípulas $4 \mathrm{~mm}$ compr.; pecíolo $5-7 \mathrm{~mm}$ compr.; lâminas elípticas a ovadas, (4-)5-12 $\times(2,5-) 3-5,5 \mathrm{~cm}$., base truncada, arredondada a subcordada, margem fortemente serreada, espinescente, com dentes agudos ligeiramente recurvados, ápice acuminado, concolores. Inflorescência terminal a subterminal em panícula de racemos, subpiramidal, ereta, multiflora; flores com pedicelos patentes ao eixo, $5-8 \mathrm{~mm}$ compr.; lobos do cálice estreitamente ovados, agudos, com duas bandas marginais mais claras; pétalas espatuladas, amarelo-ouro, 6-8 mm compr., ápice obtuso a subemarginado; anteras com bordos sinuosos, $4 \mathrm{~mm}$ compr. Frutos com receptáculo expandido verde-avermelhado, $8 \mathrm{~mm}$ diâm., mericarpos verde-escuros ovóides, $10 \mathrm{~mm}$ compr. Material selecionado: Canaã dos Carajás, FLONA de Carajás, Serra Sul, S11A, Lagoa das Três Irmãs, $6^{\circ} 20^{\prime} 59^{\prime \prime}$ 'S, 50²6'48”'W, 741 m, 20.X.2016, fr., L.V. Vasconcelos et al. 1043 (MG); S11C, capão próximo à Lagoa do Amendoim, 6²3'43”'S, 50²2'39”'W, 767 m, 17.IX.2016, fl., L.V. Vasconcelos et al. 977 (MG); Serra da Bocaina $6^{\circ} 18^{\prime} 41^{\prime \prime} \mathrm{S}, 49^{\circ} 52^{\prime} 11^{\prime \prime} \mathrm{W}, 700 \mathrm{~m}$, 25.IX.2012, fr., H.C. Lima e D.F. Silva 7572 (MG, RB). Parauapebas, Serra Norte, N1, 6 ${ }^{\circ} 00^{\prime} 53^{\prime \prime}$, $50^{\circ} 17^{\prime} 52^{\prime \prime} \mathrm{W}$, 715 m, 24.XI.2009, fr., R.D. Ribeiro et al. 1368 (MG), N4, 605'23"'S, 50¹1'33”'W, 13.III.2015, fl., L.C. Lobato et al. $4314(\mathrm{MG})$.

Distinta das outras espécies do gênero devido às suas folhas fortemente denteadas com acúleos pungentes densamente dispostos e inflorescências ramificadas, Ouratea castaneifolia possui frutos chamativos procurados por aves.
Ouratea castaneifolia é amplamente distribuída na América tropical, tendo sido registrada na Bolívia, Colômbia, Venezuela e nas Guianas (Sastre 2003). No Brasil ocorre em todas as regiões, exceto no Sul do país. Na Amazônia ainda não foi registrada no Acre, Roraima, Rondônia e Amapá (BFG 2015). Na Serra dos Carajás ocorre em capões sobre canga e isoladamente, tanto na Serra Norte: N1 e N4, quanto na Serra Sul: S11A, S11C e na Serra da Bocaina.

1.2. Ouratea racemiformis Ule, Notizbl. Bot. Gart. Berlin 6: 335 (1915).

Fig. 1c; $2 \mathrm{c}-\mathrm{d}$

Arbusto a arvoreta 1,5-2,5 $\mathrm{m}$ alt., totalmente glabro, ramos pendentes. Estípulas multinervadas, naviculares, $5 \mathrm{~mm}$ compr.; pecíolo 5-10 $\mathrm{mm}$ compr.; lâminas lanceoladas, oblongas ou estreitamente elípticas, $8-16 \times 2,5-5 \mathrm{~cm}$., base arredondada a aguda, margem levemente serreada, com dentes curtos, não espinescente, ápice longamente acuminado, concolores. Inflorescência terminal racemiforme, pêndula, multiflora; flores com pedicelos curvos em relação eixo, 3-5 mm compr.; lobos do cálice estreitamente ovados, agudos, decíduos na antese; pétalas elongadas, amareloclaras, 10-12 mm compr., ápice agudo; anteras com bordos sinuosos, $8 \mathrm{~mm}$ compr., creme com estrias castanhas. Frutos com receptáculo expandido avermelhado, 6-8 mm diâm., mericarpos verdeescuros ovóides, $8 \mathrm{~mm}$ compr.

Material selecionado: Canaã dos Carajás, Serra Sul, S11D, 29.VI.2013, fl., R.S. Santos et al. 95 (MG). Parauapebas: N1, 14.V.1982, fl., R.S. Secco 197 (MG); N3, capão, 15.VI.2017, fl., M.V. Wardil et al. 266 (MG); N4, 20.III.1984, fl., A.S.L. Silva 1927 (MG); N6, 607'51'S, 50¹0’39”W, 694 m, 13.VIII.2016, fl., R.M. Harley et al. 57976 (MG). 
Ouratea racemiformis difere das outras espécies do gênero devido às suas folhas lanceoladas, oblongas ou estreitamente elípticas e pouco denteadas e pela inflorescência simples, pêndula, portando flores com pétalas amarelo-claras, elongadas.
Ouratea racemiformis é aparentemente endêmica do Brasil (BFG 2015), tendo sido registrada no Maranhão e na região Norte para os estados do Amazonas, Amapá e Pará. Na Serra dos Carajás ocorre em capões sobre canga perto de
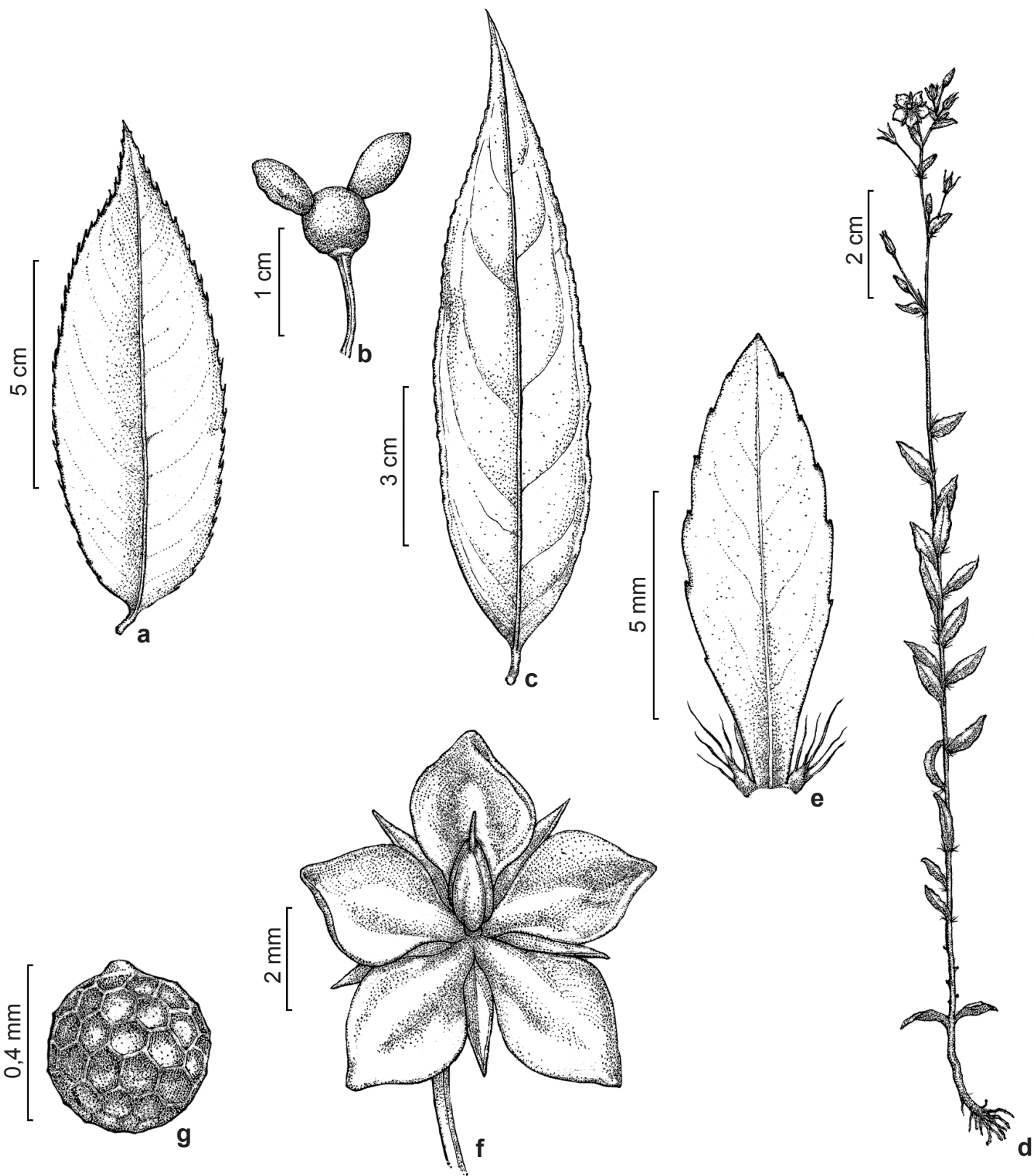

Figura 1 - a-b. Ouratea castaneifolia - a. folha; b. fruto com receptáculo expandido. c. Ouratea racemiformis - folha. d-h. Sauvagesia tenella - d. hábito; e. folha com estípulas; f. flor; g. semente. (a-b. L.V. Vasconcelos 1043; c. M.V. Wardil 266; d-h. L.V. Vasconcelos 1090). Ilustrações: João Silveira.

Figura 1 - a-b. Ouratea castaneifolia - a. leaf; b. Fruit with expanded receptacle. c. Ouratea racemiformis - leaf. d-h. Sauvagesia tenella - d. habit; e. leaf with stipules; f. flower; g. seed. (a-b. L.V. Vasconcelos 1043; c. M.V. Wardil 266; d-h. L.V. Vasconcelos 1090). Illustrations: João Silveira. 
lagoas e na floresta ombrófila aberta, tanto na Serra Norte: N1, N3, N4 e N6, como na Serra Sul: S11D.

\section{Sauvagesia L.}

Ervas anuais ou perenes a subarbustos ou arbustos, terrestres ou anfíbias. Estípulas pareadas persistentes, frequentemente com margens glandulosas ou apêndices com a ponta glandular, folhas opostas, às vezes agregadas em pseudo-rosetas, com margens denteadas, serreadas, crenadas ou longamente ciliadas. Flores axilares ou agrupadas em inflorescências terminais ou sub-terminais, cálice com margens glandulares, pétalas brancas, rosadas, lilases ou magenta, corona envolvendo os estames e persistindo no fruto; estames 5, com deiscência poricida, gineceu ovóide com estilete apical. Fruto capsular protegido pelo cálice e pela corona persistente, deiscente por uma fenda lateral liberando muitas sementes castanhas, foveoladas. As espécies de Sauvagesia diferem quanto à sua corona, que pode ter dois ciclos, com o externo filamentoso e o interno petaloide ou
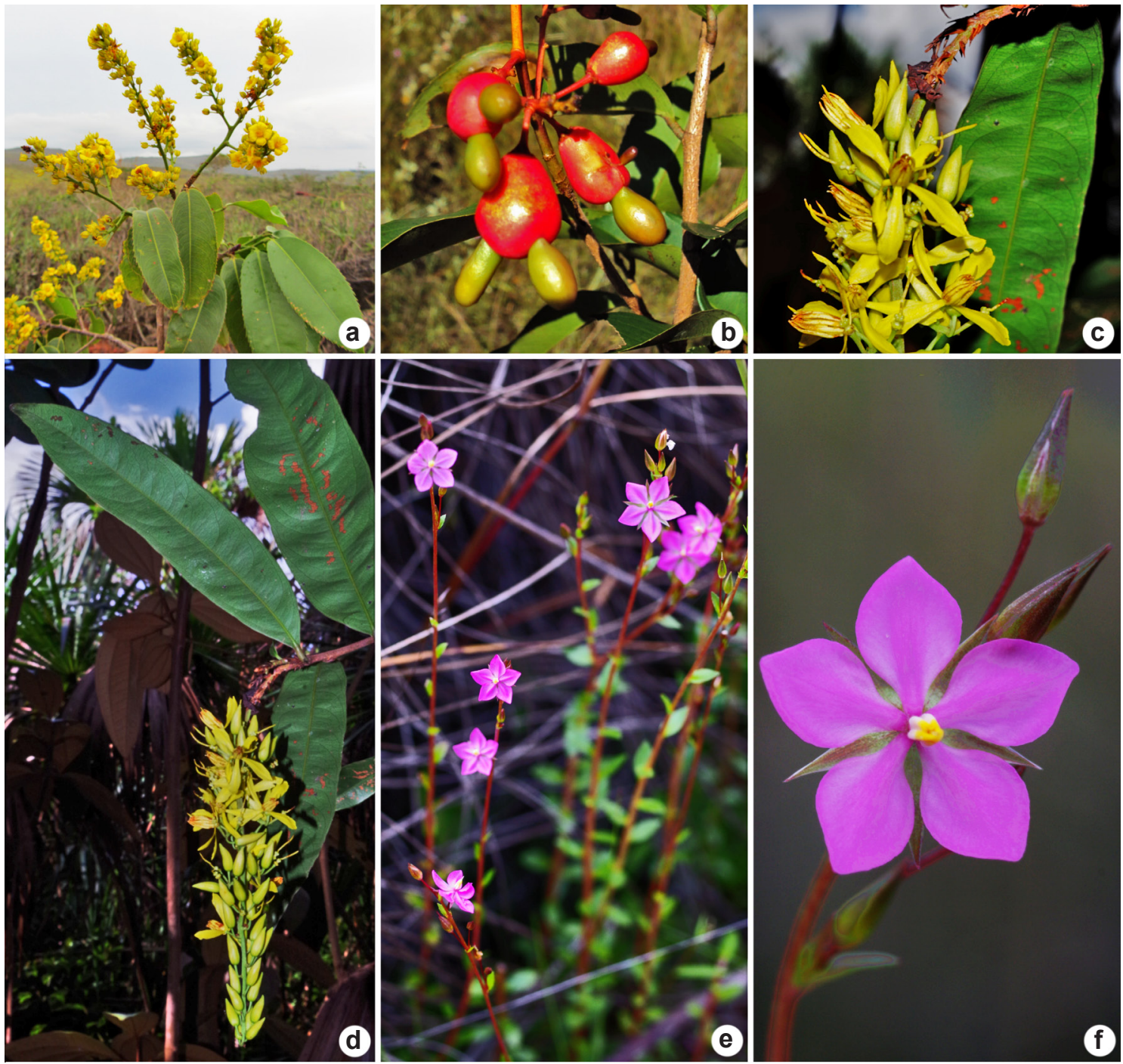

Figura 2 - a-b. Ouratea castaneifolia - a. inflorescência; b. frutos. c-d. Ouratea racemiformis - c. detalhe das flores; d. inflorescência. e-f. Sauvagesia tenella - e. plantas no habitat; f. flor em vista frontal. Fotos: a. M.E.L.Lima; b. L.V. Vasconcelos; c-d. N.F.O. Mota; e-f. P.L. Viana.

Figure 2 - a-b. Ouratea castaneifolia - a. inflorescence; b. fruit. c-d. Ouratea racemiformis - c. close up of flowers; d. inflorescence. e-f. Sauvagesia tenella - e. plants in habitat; f. flower, frontal view. Photos: a. M.E.L.Lima; b. L.V. Vasconcelos; c-d. N.F.O. Mota; e-f. P.L. Viana. 
apenas um ciclo (Chacon et al. 2003; Salvador et al. 2010). Gênero com 40 espécies ocorrendo em áreas abertas (Zappi \& Lucas 2002) conta com 33 espécies brasileiras das quais 11 estão registradas para o Pará (BFG 2015). Em Carajás há registros de Sauvagesia erecta L., uma planta ruderal amplamente distribuída nos trópicos, mas que não parece ocorrer sobre a canga.

2.1. Sauvagesia tenella Lam., Tabl. Encycl. 2: 117. 1797.

Fig. 1d-g; 2e-f

Erva anfíbia, $10-25 \mathrm{~cm}$ compr., ereta, geralmente não ramificada na base e com poucos ramos laterais, todos eretos, avermelhados. Estípulas fimbriadas, (1-)3-5 partidas, cerdas com ápice glandular; folhas sésseis, lanceoladas a estreitamente espatuladas, 5-15 × 1-4 mm., base truncada, margem denteada com ápice dos dentes recurvados, ápice agudo a acuminado, discolores. Inflorescência terminal e subterminal multiflora, flores com pedicelos ascendentes, 4-8 mm compr., avermelhados; lobos do cálice elípticos, longamente acuminados, avermelhados; pétalas obovadas, rosa a lilases, 4-5 mm compr., ápice obtuso; corona alva, translúcida, em uma única série e encobrindo os estames, anteras amarelas, estilete ereto, rosado. Cápsula ovóide com sépalas, corona e estilete persistentes, deiscente por fenda lateral; sementes ovoides, reticuladas, castanhas.

Material selecionado: Canaã dos Carajás, Serra Sul, S11 A, Lagoa das Três Irmãs, $6^{\circ} 20^{\prime} 36^{\prime}$ 'S, 50 $25^{\circ} 23^{\prime}$ 'W, 749 m, 14.I.2017, fl. e fr., L.V. Vasconcelos et al. 1090 (MG); S11D, 6²4'00"S, 50¹8'56”W, 20.V.2014, fl., R.S. Santos et al. 206 (MG); Serra da Bocaina, 6¹9'49”'S, 4958'32”'W, 708 m, 16.VI.2016, fl. e fr., M. Pastore et al. 386, 387(cf.) (MG). Parauapebas, N1, 62'29'S, 50¹7'13”'W, 683 m, 6.V.2016, fl., M. Pastore et al. 317 (MG); N2, 3.V.1983, fl., M.F.F. Silva et al. 1339 (MG); N4, 605'54'S, 50¹1'36”'W, 670 m, 13.VIII.2016, fl. e fr., R.M. Harley et al. 57960 (MG), N6, 607'49'S, 50¹0'29”'W, $694 \mathrm{~m}$, 7.V.2016, fl. e fr., M. Pastore et al. 320 (MG); N8, $6^{\circ} 02^{\prime} 01$ 'S, $50^{\circ} 09^{\prime} 29^{\prime}$ 'W, 18.III.2015, fl., L.C. Lobato et al. $4337(\mathrm{MG})$.

Sauvagesia tenella forma grandes populações em Carajás, onde foi observada tanto como erva ereta não ramificada com até $10 \mathrm{~cm}$ de altura, como erva ramificada especialmente na metade distal e atingindo $25 \mathrm{~cm}$ de altura. Os espécimes mais robustos relembram Sauvagesia sprengelii A.St.-Hil., porém esta espécie distingue-se por apresentar ramos mais lenhosos (subarbustivos) e possuir folhas mais densamente distribuídas nos ramos. Apesar de não haver coletas disponíveis da ubíquita Sauvagesia erecta na área, é possível que espécimes com folhas maiores e padrão de ramificação ao longo de toda planta (ver Pastore 387) sejam intermediários ou híbridos entre as duas espécies.

Sauvagesia tenella possui ampla distribuição na região neotropical, ocorrendo desde Belize até a Bolívia, em restingas, savanas arenosas, campinaranas e locais periodicamente alagados. No Brasil é registrada na região Norte (exceto nos estados do Acre, Amapá e Rondônia), Mato Grosso, Mato Grosso do Sul e Goiás e Piauí (BFG 2015). Na Serra dos Carajás é registrada em lajedos de canga da Serra Norte: N1, N2, N4, N6 e N8, Serra Sul: S11A, S11D e Serra da Bocaina.

\section{Agradecimentos}

A autora agradece ao Instituto Tecnológico Vale (01205.000250/2014-10) e CNPq (455505/2014-4), o financiamento; a Marcos Enoque Leite Lima, Nara F.O. Mota e Pedro Lage Viana, as fotografias cedidas, a Nara Mota, a montagem da prancha de fotos e a João Silveira, a arte.

\section{Referências}

BFG - The Brazil Flora Group (2015) Growing knowledge: an overview of seed plant diversity in Brazil. Rodriguésia 66: 1085-1113.

Botelho DLC \& Rocha AES (2018) Flora das cangas da Serra dos Carajás, Pará, Brasil: Quiinaceae. Rodriguésia 69: 1369-1371.

Chacon RG, Yamamoto K \& Cavalcanti TB (2003) Ochnaceae. In: Cavalcanti TB \& Ramos AE (orgs.) Flora do Distrito Federal. Brasil. Vol. 3. Embrapa, Distrito Federal. Pp 207-225.

Fiaschi P, Fraga CN \& Yamamoto K (2010) Neotropical Ochnaceae s.1. (incl. Quiinaceae). In: Milliken W, Klitgaard B \& BaracatA(2009 onwards) Neotropikey - Interactive key and information resources for flowering plants of the Neotropics. Disponível em <http://www.kew.org/science/tropamerica/ neotropikey/families/Ochnaceae s.1. (incl. Quiinaceae).htm>. Acesso em 19 fevereiro 2018.

Salvador GS, Cervi AC, Brotto ML \& Santos EP (2010)A família Ochnaceae DC. no estado do Paraná, Brasil. Acta Botanica Brasilica 24: 423-434.

Sastre C (2003) Ochnaceae. In: Steyermark JA, Berry PE, Yatskievych K \& Holst BK (eds.) Flora of the Venezuelan Guayana. Vol. 7. Missouri Botanical Garden, Saint Louis. Pp. 124-161.

Schneider JV, Bissiengou P, Amaral MCE, Tahir A, Fay MF, Thines M \& Chatrou LW (2014) 
Phylogenetics, ancestral state reconstruction, and a new infrafamilial classification of the pantropical Ochnaceae (Medusagynaceae, Ochnaceae s.str., Quiinaceae) based on five DNA regions. Molecular Phylogenetics and Evolution 78: 199-214.
Yamamoto K \& Sastre C (2004) Flora de Grão Mogol, Minas Gerais: Ochnaceae. Boletim de Botânica da Universidade de São Paulo 22: 343-348.

Zappi DC \& Lucas E (2002) Sauvagesia nitida Zappi \& E. Lucas (Ochnaceae): a new species from Catolés, Bahia, NE Brazil. Kew Bulletin 57: 711-717.

\section{Lista de exsicatas}

Bastos MN 482 (2.1). Carreira LMM 3388 (2.1). Cavalcante PB 2096 (2.1), 2621 (2.1), 2660 (2.1). Daly DC 1992 (2.1). Fernandes GEA 46 (2.1). Harley RM 57960 (2.1), 57976 (1.2). Lima HC 7572 (1.1). Lobato LC 4314 (1.1), 4337 (2.1). Nascimento OC 959 (2.1). Oliveira AT in UEC 18515 (1.1). Oliveira RC 2569 (2.1). Pastore M 317 (2.1), 320 (2.1), 386 (2.1?), 387 (2.1). Reis AS 95 (2.1). Ribeiro RD 1368 (1.1). Rosa NA 1812 (2.1). 4247 (2.1), 4639 (1.2). Santos RS 95 (1.2), 132 (1.1), 206 (2.1), 224 (1.2). Secco RS 197 (1.2), 225 (2.1), 420 (2.1), 580 (1.1). Silva ASL 1812 (2.1), 1927 (1.2). Silva CAS 571 (1.1). Silva MFF 1339 (2.1). Silva MG 3028 (2.1). Sperling CR 5645 (2.1). Vasconcelos LV 977 (1.1), 1043 (1.1), 1090 (2.1). Wardil MV 266 (1.2). Zappi DC 3551 (1.2).

Editor de área: Dr. Pedro Viana Artigo recebido em 08/02/2018. Aceito para publicação em 16/03/2018. This is an open-access article distributed under the terms of the Creative Commons Attribution License. 